\title{
Growth of ICT Capital and Deceleration of Labour Productivity in the EU Countries: The Missing Links
}

\author{
Pradip Kumar Biswas ${ }^{1} \&$ Alberto Moreira Baptista ${ }^{2}$ \\ ${ }^{1}$ CSIR-NISTADS, India \\ ${ }^{2}$ CETRAD/UTAD, Portugal \\ Correspondence: Pradip Kumar Biswas, CSIR-NISTADS, India. E-mail: pkbiswas1963@gmail.com
}

Received: July 4, 2012 Accepted: July 19, 2012 Online Published: August 2, 2012

doi:10.5539/cis.v5n5p55

URL: http://dx.doi.org/10.5539/cis.v5n5p55

\begin{abstract}
Labour productivity in most of the EU countries grew much slower than in US over the last one and a half decades and the difference is attributed to the difference in the use of ICT. Analysing EU KLEMS database (capital (K), labour (L), energy (E), material (M) and service inputs (S)) and Eurostat database it is noted that the micro and small enterprises, numerically predominant in the EU countries, use much less amount of ICT. With very low proportion of enterprises with ICT installation, with less sophisticated technology and probably with the lowest amount of ICT capital, these enterprises employ relatively larger proportion of workers who use ICTs. The larger enterprises on the other hand with more sophisticated and larger quantity ICT capital employ fewer workers who handle this technology. An implication of this is the fast growth of productivity of selected highly ICT skilled workers of the larger enterprises leaving rest of the workforce to benefit least from the technology. It is obvious under this situation that the overall productivity growth of the workers would be stunted.
\end{abstract}

Keywords: Information and Communication Technology, labour productivity, skill, SME, microenterprise

\section{Introduction}

Following the observation of Solow (1987) about the non-existence of any estimation of productivity associated with the application of computer despite its widespread use, several studies have been made on the US firms probing the economic implications of the use of information technology as well as communication technology in the production process (Note 1). Tracing this productivity was however a monumental task as it called for redefining the concept of national accounting, for example expenditure on software was now treated as investment rather than intermediate consumption as used to be defined earlier, and based on this concept collection, compilation, processing and interpretation of data. Nonetheless these studies highlighted significant growth of labour productivity due to the growth of the use of computer and communication technology (ICT) by the enterprises across several sectors in the US economy (Note 2). It directly benefits the users in storing, retrieving, processing and dissemination of information in large quantities with very less time thus help the business in decision making and also in the innovation process through knowledge creation and quick diffusion. It is further noted that ICT has become a general purpose technology. Its widespread use would create greater network externality and scope for new areas of applications and innovations inducing firms to make complementary investments in human capital and organisational innovations (Note 3). Being a general purpose technology its specific utilisation would require co-innovation and further investment by the enterprises (Note 4).

Inspired by these observations EU member states that were mostly lagging behind the US in the use of ICT have placed greater role on ICT as a vehicle for future development of the EU. In the Lisbon Treaty (2000) the European Council has adopted three pillars of development, namely, economic, social and environmental:

- An economic pillar preparing the ground for the transition to a competitive, dynamic, knowledge-based economy. Emphasis is placed on the need to adapt constantly to changes in the information society and to boost research and development.

- A social pillar designed to modernise the European social model by investing in human resources and combating social exclusion. The Member States are expected to invest in education and training, and to conduct an active policy for employment, making it easier to move to a knowledge economy. 
- An environmental pillar, which was added at the Göteborg European Council meeting in June 2001, draws attention to the fact that economic growth must be decoupled from the use of natural resources.

Widespread use of ICT in businesses as well as in domestic purposes is thought to be essential for building an information society and an important factor towards attaining the "Lisbon Goal" of higher growth, more and better jobs and greater social inclusion by 2010. This would generate growth impetus in their long stagnant labour productivity and would also bridge the productivity gap with the advanced countries, notably, USA.

Available estimates indicate that after adoption of the policy of building information society there has been substantial increase in the use of ICT both by the firms and households. The share of ICT capital in total real fixed capital in these countries increased considerably. However, labour productivity in most of these economies grew rather slowly during this period. These disparate trends in ICT use and labour productivity call for an explanation. The present paper aims at providing such an explanation. Thus, the scheme of the paper is as follows:

While the present one is introductory, section 2 provides an account of the growth of ICT use and labour productivity and notes the disparate trends of high ICT growth and deceleration of labour productivity. Section 3 reviews literature and formulates plausible hypotheses for the explanation of these disparate trends. A discussion of the sources of data is made in section 4. Section 5 analyses the diffusion of ICT across size classes of enterprises with 10 or more workers and across industries. It then looks into the use of ICT by the workers of these enterprises and sectors. Based on limited available data on the ICT use by very small enterprises in selected countries section 6 presents a comparative analysis of ICT use by enterprises and their workers for an explanation of the disparate trends. Finally a succinct summary and some concluding observations are made in section 7.

\section{Estimates of ICT Capital and Labour Productivity in Selected EU Countries}

There has been a rapid growth of ICT capital in the EU countries which even started much before the Lisbon Treaty (2000) when the member countries agreed to take ICT capital to mass level. As a result of this growth most of these countries substantially raised their share of ICT capital (including software) in the stock of real fixed capital (Table 1). The largest rise of this share took place in UK where the share jumped up from $3.69 \%$ in 1995 to $8.25 \%$ in 2000 and further to $13.03 \%$ in 2005. Similarly Austria, Denmark, Portugal, Slovenia, Netherlands and Sweden raised their ICT share in the range of 7-10\% by 2005. In Finland, Czech Republic, Italy and Austria the share lies between 6 to 7 percent in 2005. Among the EU countries Germany has a comparatively low figure of $4.79 \%$ which may be compared with the corresponding figure of Japan that stands at $5.33 \%$. Despite rapid growth EU countries are far behind the US, even the highest percentage figure of UK in 2005 was far exceeded by US ten years before. In 2005 ICT capital contributes more than 42 percent of the US total fixed capital.

Table 1. Percentage share of ICT capital in total fixed capital

\begin{tabular}{llllllll}
\hline Country & 1995 & 2000 & 2005 & Country & 1995 & 2000 & 2005 \\
\hline UK & 3,69 & 8,25 & 13,03 & Italy & 3,02 & 4,87 & 6,04 \\
Austria & 2,00 & 3,71 & 5,97 & Germany & 2,23 & 3,51 & 4,79 \\
Sweden & 4,11 & 6,39 & 7,41 & Finland & 2,38 & 4,53 & 6,26 \\
Slovenia & 9,26 & 8,32 & 9,27 & Denmark & 1,9 & 4,91 & 9,62 \\
Portugal & 2,01 & 5,82 & 9,48 & Czech Republic & 2,19 & 5,07 & 6,64 \\
Netherlands & 2,5 & 4,97 & 7,63 & USA & 17,75 & 36,37 & 42,39 \\
Japan & 2,99 & 4,19 & 5,33 & & & & \\
\hline
\end{tabular}

Source: EU KLEMS database.

It is striking to note that despite the special emphasis of the Lisbon Treaty to raise labour productivity through greater use of information and communication technology and the subsequent rise in the use of this technology, the growth of labour productivity slowed down in most of the EU countries as shown in Table 2. Only a few countries like Lithuania, Latvia, Slovak and Czech Republic could raise their labour productivity during 2000-07 over 1995-00. Most others primarily advanced and middle level countries, like Austria, UK, Germany, France, Italy, Denmark, Belgium, etc. witnessed a decline in the growth rate of labour productivity. For comparison with few other advanced countries in the world we have taken Japan and USA. In Japan a similar decelerating trend in 
labour productivity is noted as in most of the EU countries. US data however indicates some accelerating trend of the productivity. Notwithstanding this general declining trend in the major EU countries in the post-Lisbon Treaty phase, some countries like Sweden, Finland and Ireland maintain growth rates that are still higher than what the US registered despite acceleration in that period. Further sectoral break up estimates of productivity growth indicates that the decline is all pervasive. In the case of manufacturing only UK, Denmark, Finland, Spain, Slovak and Czech could raise labour productivity growth, and the countries like Sweden and Ireland despite decline in the second period maintained growth rates of labour productivity much higher than that of the US manufacturing. In wholesale and retail only UK, Finland, Belgium, Latvia and Slovak raised the growth rate. In real estate, education and health and social work barring few exceptions the rate of labour productivity growth generally declined. This widespread deceleration of productivity in most of the EU countries was noted in several studies and, in fact, these studies found that the deceleration process started much early in the mid 1990s (Note 5).

This decline in the rate of labour productivity grow is not caused by any higher growth of employment (measured in annual hours of work) under which low skilled workers are employed at disproportionately high rate leading to reduction in average labour productivity. In fact, the employment growth also declined in most of these countries during the second period. It may be seen in Table 3 that a major decline of the employment growth took place in Belgium, Spain, Finland, Ireland, Netherlands, Portugal and Sweden all of which, excepting Spain, also had deceleration in labour productivity. Spain had a very low growth rate $(0.11 \%)$ of labour productivity in the first period. In other words, the period 1995-2000 was characterised by higher employment growth as well as higher labour productivity growth as compared to the period 2000-07. All this happened despite greater utilisation and substantial accumulation of ICT capital in the second period. Thus, there can be many reasons for this deceleration, such as due to business cycle (Note 6), but the point is that a fast growth of ICT capital failed to sustain the momentum of the productivity growth that started earlier.

Table 2. Growth rate of gross value added per labour hour (\%)

\begin{tabular}{|c|c|c|c|c|c|c|c|c|c|c|c|c|c|c|}
\hline & \multicolumn{2}{|c|}{ All Sectors } & \multicolumn{2}{|c|}{ Manufacture } & \multicolumn{2}{|c|}{$\begin{array}{c}\text { Wholesale \& } \\
\text { retail }\end{array}$} & \multicolumn{2}{|c|}{$\begin{array}{c}\text { Transport \& } \\
\text { communication }\end{array}$} & \multicolumn{2}{|c|}{ Real estate } & \multicolumn{2}{|c|}{ Education } & \multicolumn{2}{|c|}{$\begin{array}{l}\text { Health \& social } \\
\text { work }\end{array}$} \\
\hline & $1995-00$ & $2000-07$ & $1995-00$ & $2000-07$ & $1995-00$ & 2000-07 & $1995-00$ & $2000-07$ & 7 1995-00 & $2000-07$ & 7 1995-00 & $2000-07$ & $1995-00$ & $2000-07$ \\
\hline Austria & 1,42 & 1,04 & 4,54 & 2,98 & 2,17 & 0,39 & 2,08 & 2,29 & $-5,13$ & $-0,29$ & $-1,06$ & $-0,28$ & 0,27 & 0,04 \\
\hline Spain & 0,11 & 0,85 & $-0,38$ & 1,80 & 1,00 & 0,94 & 2,28 & 0,70 & $-2,69$ & $-0,95$ & 1,55 & 0,65 & $-0,29$ & $-0,24$ \\
\hline Germany & 1,98 & 1,56 & 2,93 & 3,30 & 2,39 & 1,67 & 4,66 & 3,48 & $-2,14$ & $-0,53$ & 0,40 & $-1,32$ & 2,58 & 1,58 \\
\hline Portugal* & 2,51 & 0,83 & 4,21 & 2,27 & 3,28 & $-1,67$ & 3,67 & 2,82 & $-1,57$ & $-1,96$ & $-0,21$ & $-0,27$ & $-0,08$ & 0,88 \\
\hline UK & 2,22 & 1,65 & 1,67 & 4,80 & 2,44 & 3,48 & 8,11 & 2,58 & 1,81 & 0,53 & $-1,68$ & $-2,05$ & 1,74 & 1,24 \\
\hline Netherlands & 1,59 & 1,48 & 3,30 & 3,21 & 4,86 & 3,08 & 5,18 & 4,35 & $-0,34$ & $-0,30$ & $-1,31$ & $-0,95$ & $-0,73$ & $-0,35$ \\
\hline Sweden & 2,49 & 2,30 & 6,25 & 5,90 & 4,10 & 3,93 & 3,05 & 3,24 & $-2,39$ & 1,05 & 0,97 & $-0,36$ & $-0,13$ & 0,21 \\
\hline Belgium & 1,21 & 1,05 & 3,55 & 2,72 & $-0,22$ & 1,80 & 0,55 & 1,98 & $-2,75$ & $-0,41$ & 0,29 & $-0,86$ & $-0,56$ & $-0,32$ \\
\hline Denmark & 0,98 & 0,38 & 1,26 & 2,73 & 2,05 & 1,05 & 2,80 & 2,69 & $-4,38$ & $-2,48$ & 1,34 & $-0,73$ & 0,66 & $-0,16$ \\
\hline Finland & 2,69 & 2,03 & 6,00 & 6,31 & 1,61 & 4,09 & 5,60 & 2,71 & $-1,81$ & $-1,34$ & 0,97 & $-0,41$ & $-0,65$ & $-2,26$ \\
\hline France & 2,02 & 1,35 & 4,40 & 2,88 & 2,00 & 0,87 & 5,37 & 3,41 & $-0,60$ & 0,84 & $-1,11$ & $-1,54$ & $-0,82$ & 0,17 \\
\hline Ireland & 4,74 & 2,82 & 9,82 & 6,56 & 4,92 & 2,12 & 4,03 & 0,86 & 6,09 & 2,99 & $-2,53$ & $-1,33$ & 0,81 & $-1,34$ \\
\hline Italy & 0,77 & 0,18 & 0,87 & 0,30 & 1,27 & 0,26 & 2,74 & 1,81 & $-4,34$ & $-2,19$ & $-0,82$ & 0,36 & 0,95 & 0,95 \\
\hline Estonia & 12,82 & 4,70 & 10,78 & 5,52 & 9,89 & 5,37 & 17,27 & 6,65 & 6,27 & 5,90 & 17,74 & $-0,03$ & 19,33 & 1,20 \\
\hline Lithuania & 5,32 & 6,42 & 9,76 & 8,22 & 5,83 & 5,85 & 4,34 & 7,02 & 8,59 & 2,00 & 3,03 & 1,40 & 9,45 & 0,06 \\
\hline Latvia & 5,48 & 6,98 & 7,57 & 6,16 & 2,84 & 9,86 & 6,36 & 6,02 & 1,25 & 5,73 & 1,40 & 4,01 & 2,12 & 5,80 \\
\hline Slovak & 3,37 & 4,04 & 4,77 & 10,78 & 2,52 & 2,76 & 1,71 & $-0,19$ & 4,56 & $-4,30$ & 6,14 & 2,19 & 7,55 & 1,95 \\
\hline Czech Rep. & 0,52 & 3,76 & 2,92 & 5,73 & 6,99 & 6,91 & 0,42 & 5,27 & $-4,29$ & 0,53 & $-0,80$ & 3,88 & $-7,92$ & 0,37 \\
\hline US & 1,62 & 1,77 & 3,60 & 3,90 & 5,15 & 2,57 & 1,35 & 4,01 & $-0,37$ & 2,09 & $-0,24$ & $-0,96$ & $-1,03$ & 0,60 \\
\hline Japan* & 2,26 & 1,97 & 5,54 & 0,28 & $-1,38$ & 1,21 & 2,19 & 0,93 & 1,97 & $-3,24$ & 1,45 & 4,86 & 2,23 & 0,28 \\
\hline
\end{tabular}

Note: (1) * For this country the second period covers 2000-06.

(2) Labour productivity is measured as gross value added per hour worked.

Source: EU KLEMS database. 
Table 3. Growth rate of total annual hours of work (\%)

\begin{tabular}{cccccc}
\hline Country & $1995-00$ & $2000-07$ & Country & $1995-00$ & $2000-07$ \\
\hline Austria & 0,83 & 0,8 & Italy & 1,01 & 1 \\
Belgium & 1,36 & 0,85 & Lithuania & $-0,61$ & 1,53 \\
Czech Rep & $-0,44$ & 0 & Latvia & 0,14 & 1,76 \\
Spain & 3,84 & 2,45 & Netherlands $^{-}$ & 2,26 & 0,44 \\
Estonia & $-2,07$ & 2,12 & Portugal $^{*}$ & 1,09 & 0,28 \\
Finland & 1,96 & 0,85 & Slovak & $-1,41$ & 0,69 \\
France & 0,66 & 0,43 & Sweden & 0,84 & 0,47 \\
Germany & 0 & $-0,2$ & UK & 0,96 & 0,77 \\
Ireland & 4,52 & 2,73 & USA & 2,07 & 0,41 \\
Japan* & $-1,02$ & $-0,67$ & & & \\
\hline
\end{tabular}

Note: * The second period covers 2000-06.

Source: EU KLEMS database.

\section{Literature Review and Hypothesis Formulation}

Micro level studies based on individual enterprise data in the EU countries reveal significant association of the use of ICT and labour productivity across industries and services sectors at varied degrees. These results reinforce the relations earlier found for the US firm level data (Note 7). It is expected that given this association of ICT and labour productivity, growth of the stock of ICT capital would also raise the growth of labour productivity and this should be reflected at the aggregate or macro level. On the contrary, macro level data indicate slowdown of labour productivity growth despite larger accumulation of ICT capital in most of the EU countries. As opposed to this, US macro data do reflect acceleration of labour productivity with the rise in ICT capital stock. The preset paper tries to explore plausible reasons for this contradiction and reconciles micro level relations with the macro trends mainly for the EU countries.

One tentative hypothesis emanating from the above observations is the inadequate diffusion of ICT among the entrepreneurs and workers is responsible for the EU's failure to take advantage of ICT in raising overall productivity. There have been several studies on the diffusion of new IT technologies across large firms, e.g., Saloner and Steinmueller (1995) and Bresnahan and Saloner (1996), who noted that business co-invention was a major barrier to adoption of ICT. Bresnahan and Trajtenberg (1995) noted that co-invention often requires "coordination between agents located far from each other along the time and technology dimension" (p. 3). However, the institutional arrangements and market structure often differ across countries and this affects the ability of the agents to successfully contract in an environment with asymmetric information and uncertain property rights (Note 8). Some other studies point out that IT investments together with organisational changes and internal training played the key role in raising the US productivity (van Ark, 2006; Brynjolfsson \& Hitt, 2003). In the case of high productivity growth in Sweden, Pettersson (2009) observed a similar process of high complementary investment in combination with the fast growth of IT capital. Pettersson (2009) made a succinct summary of the literature dealing with various complementary factors needed for the ICT capital to be successfully adapted and deployed most productively as follows:

Several studies indicate that there is a need for complementary investments in organisation and internal training in order for the companies' IT investments to achieve their full impact (see, for example, van Ark, 2006, Brynjolfsson, 2003). Studies based on US data show that work routines, further training, and the use of IT are important determinants for productivity (see, for example, Andersson \& Ådahl, 2005). The percentage of employees that use computers in their work and their level of education are factors that have a positive impact on productivity (see Black \& Lynch, 2001, data for the period 1987-1993). Studies also show that the greatest positive effects of reorganisation processes on productivity occur in companies with a high percentage of highly-educated labour (see Caroli \& van Reenen, 2001). The level of education of the employees of a company is decisive not only in terms of making it possible to rapidly reap the benefits of new technology but also for recognize processes leading to positive effects (Aghion, Caroli, \& Garcia-Penalosa, 1999). One study also shows that US multinational companies in the UK are more productive than British companies. The explanation may be 
that US companies export their organisational structures to subsidiaries in other countries (see Bloom, Sardun, \& van Reenen, 2007). Evidence of similar positive effects has been found in Sweden (see Karpaty, 2007).

It is however rightly pointed out by Spiezia and Vivarelli (2002) that the microeconomic empirical evidence usually overestimates the positive effects of technological change. For example, product innovation as a result of the introduction of new technology would raise employment even when the technology being labour-saving as the innovating farms would gain market share. This estimation of employment impact however does not take into account the effects on the competitors who would be competed out and the consequent loss of jobs. An industry level analysis would be more appropriate as the data capture new jobs created by the innovating firms and the impact on competitors at the end of diffusion process. Spiezia and Vivareli further noted that even sectoral-level studies fail to capture all the direct and indirect effects of technology as they do not take into account all compensation mechanisms that operate outside the sector originally affected by IT use. It is therefore suggested that only aggregate studies could do that. This is probably one of the reasons why despite strong impact of the various ICT capitals on firm level productivity in the EU countries along with substantial growth of the ICT capital, economy-wide aggregate productivity did not grow fast. The linkages between micro and macro levels may be better understood by looking at the adoption of technology and its impacts for different segments of the economy simultaneously. Further, if the technology is widely distributed across firms and sectors, the possibility of over estimation would be much less and there would be a possibility of underestimation if the technology, particularly ICT, spread sufficiently to generate externality such as through knowledge spill over. Based on this premise of the greater social benefit of the ICT through widely distributed use by the enterprises and workers we will see to what extent the technology diffused among enterprises and to what extent the workers use it.

The distribution of ICT capital across size classes of enterprises and across sectors as well as their uses by the workers would provide an indication of the depth and breadth of ICT diffusion. If the diffusion is not wide spread but concentrated among the larger enterprises or in selected sectors leaving aside a majority of the enterprises or sectors outside the ambit of ICT then obviously the benefit will not be reflected at the macro level even though the selected ICT using firms may gain productivity. Further, the use of ICT at the enterprise level may be useful for better business planning and communication and work coordination but the proportion of workforce actually using the ICT would also be an important factor in determining labour productivity. Installation of ICT just for fashion - as all other enterprises are doing that or as government is insisting - would have a little contribution to the growth of productivity. It needs to be used by a majority of the workers in order to raise their productivity.

Since the tiny enterprises are the most important in terms of the number of enterprises and employment generation, any rise in productivity of these workers would have greater macro reflection; we would also see how ICT has been diffused among these enterprises and their workers. As already mentioned that there may also be several other problems of raising productivity from ICT use, such as inadequate skill up-gradation of the workforce, as it is difficult to raise ICT skills of the people of higher age, failure of the enterprises to make the required organisational change which requires highly risky complementary investments or the benefit extracted by one enterprise at the cost of others as a simple zero sum game without having any externality or innovations for market expansion (Note 9). The present exercise would however focus primarily on the diffusion of the technology across enterprises and sectors and their uses by the workers.

\section{Research Method and Data Source}

Eurostat database provides detailed statistics on the use of ICT by the enterprises across sectors (NACE based classification) and size classes for the EU countries since 2002. It includes the use of specific technologies like, intranet, internet or broadband, RFID, specific software like CRM and ERP, purposes of using the technology, such as for business communication, submitting e-invoices, online purchase/sale, automated data exchange, supply chain management, persons identification or access control, and the like. It also provides the estimates of the proportion of workers uses different types of information and communication technology starting from simple computer to internet, broadband, etc.

Analysing and comparing this Eurostat database we would see the proportion of enterprises use some basic technologies, namely computer, internet and broadband, and the proportion of workers use computer and internet at various levels of (dis-) aggregation (across size classes of enterprises as well as across sectors of activities). One of the problems with the data base is the inadequate coverage of the tiny enterprises (i.e., those with less than 10 workers). Eurostat denoted the enterprises with less than 10 workers as Very Small Enterprises (VSEs) which are further subdivided into Mini Enterprises (MI) with 5-9 workers and Micro Enterprises (MC) with 4 or 
fewer workers. For several EU countries VSEs data are not collected, for some other countries MI and MC break up data are available and for some others only MI data or aggregate VSE data are available for some years. Even for a few countries disaggregated MI and MC data are presented for some years and for other they are clubbed as VSEs.

Although the ICT use data have been collected since 2002, EU level aggregation is available since 2003. There have also been changes in the grouping of sectors, and over the years coverage is widened and as new ICT tools are introduced and new uses are made, they are subsequently included in the database.

\section{Diffusion across Sectors and Enterprises with 10 or More Workers}

There are several items of ICT capital with varied levels of sophistication which are used by the enterprises for innumerable purposes; we would however see to what extent the simple useful items like computer, internet and broadband are diffused among the enterprises and sectors. Tables 4 and 5 present summary estimates of installation of these ICT items by the enterprises with 10 or more workers for the EU15 and EU25 countries respectively. In the EU15 countries, more than 93 percent of the enterprises with 10 or more workers have already installed computers by 2003 which steadily rose to 96 percent by 2005 and around 98 percent by 2009 approaching almost to a saturation level. Sector-wise break up data do not indicate much variation in the percentage of enterprises installing computers in different sectors. Size-class wise break up estimates reveal minor asymmetry in the distribution of computer installation across large, medium and small enterprises - as compared to the medium enterprises it was slightly lower for small enterprises and slightly higher for large enterprises in 2003 and their gaps further narrowed down over the years. Proportion of enterprises with internet connection considerably lags behind the proportion for computer application for each of the sectors in 2003 . This difference is primarily due to delayed adoption of internet by the small enterprises as may be seen in Table 4 . For the medium and large enterprises this gap is very small. This disparity between small and large enterprises gradually reduced and became insignificant in 2009. Broadband technology or high speed internet connection used for bulk data transfer was adopted by the enterprises very slowly and also there is considerable variation across sectors and size classes. By 2003 around 40 percent of all the enterprises with 10 or more workers installed broadband which rose to 65 percent by 2005 . For the small enterprises it was 36.10 percent and for the large enterprises it was 77.43 percent in 2003 while the respective figures for 2005 were 61.37 percent and 93.20 percent. Among the four major sectors in manufacturing the adoption was the lowest with 36.41 percent and for the real estate, renting and business services it was the highest with 55.09 percent in 2003 and the corresponding figures for 2005 were 62.33 percent and 74.79 percent. All these sectors and classes continued to raise their adoption in the subsequent years considerably narrowing their relative disparity.

The rate of the installation of specific ICT capitals by enterprises across sectors and size-classes as observed for EU15 countries is not much different from the EU25 countries for the years 2005 and 2009. For computer installations both are almost same and for internet and broadband EU15 figures are slightly higher than the corresponding EU25 figures. This reflects the fact that the new member states are almost catching up the incumbents as regards installation of some basic ICT capitals.

Table 4. ICT use by enterprises in EU15 countries

\begin{tabular}{lccccccccc}
\hline & \multicolumn{3}{c}{ \% enterprises use computer } & \multicolumn{3}{c}{ \% enterprises with internet } & \multicolumn{2}{c}{ \% enterprises with broadband } \\
\hline Items & 2003 & 2005 & 2009 & 2003 & 2005 & 2009 & 2003 & 2005 & 2009 \\
10_DFGHIJKO (1) & 93,20 & 96,08 & 97,84 & 84,84 & 91,94 & 96,07 & 39,56 & 65,24 & 88,44 \\
10_D & 95,33 & 95,99 & 97,85 & 86,65 & 91,96 & 95,91 & 36,41 & 62,33 & 88,00 \\
10_G & 95,04 & 96,50 & 98,09 & 85,20 & 91,63 & 96,03 & 41,15 & 67,41 & 89,26 \\
10_I & 95,33 & 94,92 & 96,73 & 86,78 & 90,72 & 94,73 & 41,54 & 62,32 & 86,77 \\
10_K & 96,40 & 96,34 & 98,42 & 91,77 & 93,84 & 97,63 & 55,09 & 74,79 & 92,61 \\
L_DFGHIJKO (1) & 99,64 & 99,70 & 99,52 & 98,73 & 99,24 & 99,28 & 77,43 & 93,20 & 97,64 \\
M_DFGHIJKO (1) & 98,78 & 99,19 & 99,43 & 95,88 & 98,24 & 98,85 & 58,70 & 82,57 & 94,82 \\
S_DFGHIJKO (1) & 94,33 & 95,43 & 97,52 & 84,64 & 90,63 & 95,50 & 36,10 & 61,37 & 87,07 \\
SM_DFGHIJKO (1) & 94,96 & 95,97 & 97,79 & 86,22 & 91,72 & 95,98 & 39,29 & 64,41 & 88,17 \\
\hline
\end{tabular}

Note: (1) For the year 2003 it includes data on the NACE categories of D (manufacturing), F (construction), G (wholesale and retail trade), $\mathrm{H}$ (hotels and restaurants), I (Transport, storage and communication), K (Real estate, 
renting and business activities) and $\mathrm{O}$ (Other community, social, personal service activities). For the years 2005 and 2009 it also includes J (financial intermediation). '10_' refers to combined size classes above 10 workers, L_ large size class, $M_{-}$refers to medium size class, $S_{-}$refers to small size class and SM_refers to small and medium combined (SMEs).

Table 5. ICT use by enterprises in EU25 countries

\begin{tabular}{lcccccc}
\hline & \% enterprises use computer & \% enterprises with internet & \% enterprises with broadband \\
\hline Items & 2005 & 2009 & 2005 & 2009 & 2005 & 2009 \\
10_DFGHIJKO (1) & 95,58 & 97,31 & 91,13 & 95,48 & 62,64 & 85,18 \\
10_D & 95,24 & 97,21 & 90,79 & 95,18 & 58,94 & 84,03 \\
10_G & 95,91 & 97,50 & 90,62 & 95,41 & 63,97 & 85,48 \\
10_I & 94,60 & 96,23 & 90,43 & 94,28 & 61,32 & 83,24 \\
10_K & 96,28 & 98,10 & 93,60 & 97,23 & 73,43 & 90,73 \\
L_DFGHIJKO (1) & 99,67 & 99,54 & 99,22 & 99,32 & 91,69 & 97,21 \\
M_DFGHIJKO (1) & 99,14 & 99,24 & 98,16 & 98,71 & 79,51 & 92,55 \\
S_DFGHIJKO (1) & 94,81 & 96,90 & 89,62 & 94,79 & 58,67 & 84,82 \\
SM_DFGHIJKO (1) & 95,46 & 97,25 & 90,89 & 95,37 & 61,77 & 84,82 \\
\hline
\end{tabular}

Note: Same as in Table 4.

Real benefit of ICT capital would however be obtained from its effective utilisation by the vast majority of the workforce. This would require the workforce to be trained in ICT and also redesigning the organisational structure and redefining job description by the enterprises. If the workforce has poor ICT skills or if the workers' ICT skills are not utilised by appropriate job description and complementary investments by the entrepreneurs, it is unlikely that the labour productivity would grow. In either case the proportion of workers using ICT would be low. Ability to use computer and internet is simply the minimum requirement for acquiring ICT handling skill. We would assume that the workers using computer or internet have the ICT skills and their number represents the extent to which the economy is prepared to use ICT through changing technology and organisational redesigning of its enterprises.

Table 6 displays the percentages of workers use computer and internet at various levels of aggregations. It may be seen that in the EU15 countries around half of the workers of the enterprises with 10 or more workers used computer in 2003 which virtually remained unchanged till 2005 and an increase of little less than 7 percentage point by 2009 . Workers using internet is still at lower proportion - only 29.48 percent in 2003 , slightly rose to 36.78 percent in 2005 and further to 45.83 percent in 2009. If one compares the rise in the proportion of enterprises installing different types of ICT capitals presented in Tables 4 and 5 with the rise in the proportion of workers using them as in Table 6, the latter is much lower. This indicates general under-preparedness of the enterprises in terms of organisational restructuring and installation of ICT compatible complementary capital or the absence of a mass of workforce with a reasonable level of ICT skill. It is thus quite evident that the low proportion of workforce using ICT has stood on the way of sustaining the high growth of labour productivity.

Sectoral break up data indicate that in real estate, renting and business services sector very large proportion of workers use computer as well as internet, as compared to other sectors. In the wholesale and retail trade sector also the percentage of workers using computer is quite high but the percentage for internet use is low. Manufacturing sector has very low proportion of workers both for using computers and for using internet. Further, the proportion of workers using computer or using internet increases with the size class of enterprises: the lowest figures for the small enterprises and the highest figures for the large enterprises. However, the disparity between small and large is much greater for the proportion of workers using computers than for the proportion of workers using internet. A comparison between EU15 and EU25 indicates that the new member states have still lower proportion of workforce using computers and internet for the years 2005 and 2009. Higher concentration of the ICT using workers in larger size-classes of enterprises and in few sectors indicates limited diffusion of the skill and technology and thus the economy as whole is yet to gain the full benefit of the technology. 
Table 6. ICT use by workers in EU countries

\begin{tabular}{lcccccccccc}
\hline & \multicolumn{4}{c}{ Percentages of workers in EU15 countries } & \multicolumn{3}{c}{ Percentages of workers in EU25 countries } \\
\cline { 2 - 11 } & \multicolumn{3}{c}{ use computer } & \multicolumn{3}{c}{ use internet } & use computer & use internet \\
\hline Items & 2003 & 2005 & 2009 & 2003 & 2005 & 2009 & 2005 & 2009 & 2005 & 2009 \\
10_DFGHIJKO (1) & 50,67 & 51,03 & 57,22 & 29,48 & 36,78 & 45,83 & 48,62 & 54,50 & 34,98 & 43,76 \\
10_D & 43,57 & 46,05 & 52,47 & 26,57 & 30,41 & 37,99 & 42,19 & 47,88 & 27,96 & 34,99 \\
10_G & 61,47 & 55,08 & 60,77 & 25,18 & 33,74 & 43,27 & 54,21 & 59,39 & 33,55 & 42,69 \\
10_I & 47,01 & 53,67 & 54,27 & 31,24 & 41,19 & 44,02 & 51,96 & 52,45 & 39,28 & 42,37 \\
10_K & 61,61 & 64,72 & 63,93 & 47,43 & 55,42 & 59,21 & 63,35 & 62,35 & 54,17 & 57,79 \\
L_DFGHIJKO (1) & 58,07 & 56,08 & 62,81 & 30,77 & 39,40 & 47,56 & 53,10 & 60,03 & 36,94 & 45,36 \\
M_DFGHIJKO (1) & 45,98 & 49,75 & 54,91 & 28,94 & 35,56 & 45,67 & 46,98 & 51,47 & 33,87 & 43,16 \\
S_DFGHIJKO (1) & 42,19 & 44,77 & 48,90 & 27,78 & 34,04 & 42,78 & 43,52 & 47,19 & 33,16 & 41,42 \\
SM_DFGHIJKO (1) & 43,89 & 47,19 & 51,66 & 28,30 & 34,78 & 44,11 & 45,23 & 49,19 & 33,51 & 42,24 \\
\hline N_E Same
\end{tabular}

Note: Same as in Table 4.

\section{ICT Use by Very Small Enterprises with 10 or Less Workers}

As already mentioned above, relevant data for the very small enterprises are not generated systematically and therefore aggregate picture at the EU15 or EU25 level is not available. However, some relevant information on VSEs are available only for seven countries, namely, Portugal, Norway, Ireland, Spain, Germany, Slovak and Slovenia which together to an extent represent EU. Further, out of these seven countries, only Germany has collected and compiled exhaustive and systematic data on VSEs with detailed MI and MC break up since 2002 and for the others the data are irregular and at best incomplete. Lack of/ incomplete or irregular statistics on VSEs of the EU member states (except Germany) shows general apathy of the states towards these entrepreneurs. It is simply assumed that if the larger enterprises modernise technology, introduce ICT and raise productivity, the same would transmit, or at least percolate, down the line to the very small enterprises. Otherwise, had the governments been serious in modernising these tiny enterprises through introducing ICT with an aim to raise their productivity, special policies and programmes would have been formulated which however would be impossible to do without concrete factual data. These enterprises deserved special attention not only because they are tiny but also due to their large collective size sharing majority of the enterprises and a significant part of employment in most of the EU countries. For instance, during 1997-2006, micro enterprises on the average constitute around 90 percent of all the enterprises of UK, and 95 percent of Spain and Portugal, and 96 percent of Italy, whereas they account for around 23 percent of the employment generated by all the enterprises in UK, 41 percent of Spain, 42 percent of Portugal and almost 50 percent in Italy (Note 10). Thus, if these tiny enterprises falter in installing ICT or effectively raising labour productivity, there would be adverse reflections at the macro level even when the larger enterprises raise their labour productivity.

It is therefore imperative to see to what extent these very small enterprises could deploy selected types of ICT capital and organise workers to use them. Based on the limited available data for the above mentioned seven countries Table 7 is constructed which shows the use of some simple ICT equipment like computer, internet or broadband by the enterprises and/or workers across size class of enterprises for each of these countries for the years 2002, 2005 and 2008. For the year 2002 estimates on VSEs are however available only for Germany which shows that around 74 percent of the MI enterprises (5-9 workers) and 46 percent, a much lower proportion, of the MC enterprises (4 or less workers) use internet. Thus within VSEs, the difference between MI and MC is quite substantial in this country with the smaller one having much lower proportion. As one moves up along the size class of enterprises, the percentage of internet using enterprises systematically rises leading to a wide difference between the small and large enterprises. Similar wide disparity between small and large enterprises is also found in Portugal, Norway, Ireland and Spain in 2002.

The distribution across size classes is however different as regards the percentage of workers using computer or internet in 2002. In Germany, MI got the highest share for computer use, and for internet use MC got the highest share followed by MI; in both the cases medium enterprises got the least percentage shares of workers engaged. For the other countries also no systematic pattern across small, medium and large enterprises is noted as regards 
the proportion of workers using computer or internet and in general the proportions are quite low in these countries, excepting Norway, in 2002. The disparate patterns of the size-class distribution of internet installation by enterprises and of the proportion of workers using internet, indicate some anomalies like under use of ICT, skill deficiency or the failure to design jobs for utilisation of computer and internet by the workers. All this militates against raising labour productivity through widespread use of ICT.

For the years 2005 and 2008 some or other information on the very small enterprises is available for all these countries excepting Spain for which relevant data are available only for the year 2005. It may be seen in Table 7 that for the countries like Portugal, Norway, Spain and Slovak the proportion of very small enterprises with internet connection was quite low. In Portugal only 32.30 percent of MI and 38.27 percent of MC enterprises used computer while 22.41 percent of the former and 25.52 percent of the latter used internet by 2005 . Between 2005 and 2008 the proportion of internet using enterprises increased substantially across all the size classes but the growth was generally higher for the VSEs with few exceptions. Yet, VSEs still remained much below their larger counterparts. The percentage share remained unchanged for MI in Slovenia which already had a very high share while in Germany the relevant share declined for MC but increased for MI. In general, MI, MC or VS enterprises have a lower intensity of internet installation as compared to the small, medium and large enterprises in all through the years. The disparity is more severe for Portugal, Ireland, Spain, Germany and Slovak.

If we look at the use of some advanced ICT like broadband, MI and MC enterprises are much more laggard and that the disparity increases not only between the VS and their larger counter parts but also among large, medium and small enterprises. Despite the overall low intensity of broadband use by the VSEs they have made substantial improvement between 2005 and 2008. For instance, in Germany only around 34 percent of MI and 47 percent of MC used broadband in 2005 which rose to 78 percent and 65 percent respectively in 2008 . The respective shases for the small and large enterprises were around 57 percent and 95 percent in 2005 and 88 percent and 97 percent in 2008. As compared to Germany, other countries like Portugal, Ireland, Spain and Slovak have even wider disparity between VSEs and other enterprises as well as between Small and large enterprises. In this regard, only Norway and Slovenia had lower disparities as compared to Germany.

As regards the proportion of workers using computer or internet, the picture was quite alarming not only for the VSEs but also for the larger enterprises. In Germany, in 2002, among the workers of the mini enterprises around 54 percent used computers and only 34 percent used internet while the same for the workers of micro enterprises were 49 percent and 36 percent respectively. For the small, medium and large enterprises, the percentages of workers using internet were even lower than those of the very small enterprises and the percentages of workers using computer were around the same as very small enterprises. In fact in 2002, all the countries excepting Norway, had very low proportion of the workers of small, medium and large enterprises (for which data are available) used internet which ranged between 10 and 24 percent. For Norway it was around 50 percent. The same may be said about computer using by the workers of larger enterprises - in Norway it was around 60 percent and for other countries it ranged between 22 and 54 percent in 2002.

The percentage of the mini enterprise workers using computers in 2005 was quite low in these countries varying between 32 percent in Portugal to 63 percent in Slovak and the range slightly moved upwards to 38 and 67 percent in 2008. The same for the micro enterprises ranged between 38 percent in Portugal and 56 percent in Slovak in 2005 and between 48 and 74 percent in 2008. As regards internet using workers the proportion is much lower: for MI it varied between 22 percent in Portugal and 52 percent in Slovak in 2005 which improved to 32 and 63 percent in 2008, while for MC the range was from 26 percent in Portugal to 43 percent in Slovak in 2005 and the same in 2008 was from 43 percent to 67 percent. The conditions of the small, medium and large enterprises are in no way better, even worse in some countries like Portugal, Germany, Slovak and Slovenia, than those of the micro and min enterprises as regards the use of computers or internet by their workers. Although, these larger size classes had much higher proportion of enterprises with the installation of internet or broadband. In general, the proportion of workers use internet or computer is quite low and lower for the larger size class of enterprises. One of the constraints seems to be inadequate availability of ICT skills as may be evident from the Community Survey Report. According to the report of "2005 Community survey on ICT usage in households and by individuals" (Demunteer, 2006) as much as $37 \%$ of the population of the age group 16-76 in EU25 have no computer skills whatsoever and another $15 \%$ have low level of computer literacy while only $26 \%$ have medium level literacy and another $22 \%$ seem to be acquainted with a wide range of computer activities. The respective figures for the employees and self-employed persons are 25\% (no basic computer knowledge), 16\% (low level knowledge), 31\% (medium level computer skills) and $28 \%$ (with high level computer skills). 
Table 7. ICT diffusion among the smaller enterprises in selected in EU countries

\begin{tabular}{|c|c|c|c|c|c|c|c|c|c|c|c|c|}
\hline \multirow[t]{2}{*}{ Country } & \multirow[t]{2}{*}{ Item } & \multicolumn{3}{|c|}{$\%$ enterprises with internet } & \multicolumn{2}{|c|}{$\begin{array}{c}\% \text { enterprises with } \\
\text { broadband }\end{array}$} & \multicolumn{3}{|c|}{$\%$ workers use computer } & \multicolumn{3}{|c|}{$\%$ workers use internet } \\
\hline & & 2002 & $2005\{2\}$ & $2008\{3\}$ & $2005\{2\}$ & $2008\{3\}$ & 2002 & $2005\{2\}$ & $2008\{3\}$ & $2002\{4\}$ & $2005\{2\}$ & $2008\{3\}$ \\
\hline \multirow{5}{*}{ Portugal } & L_DGHIK & 98,32 & 100,00 & 100,00 & 96,27 & 97,92 & 38,84 & 36,34 & 45,03 & 21,47 & 21,05 & 33,65 \\
\hline & M_DGHIK & 91,30 & 98,05 & 99,14 & 82,54 & 88,84 & 32,33 & 30,54 & 36,23 & 18,37 & 20,80 & 29,45 \\
\hline & S_DGHIK & 63,57 & 78,44 & 94,07 & 59,11 & 83,86 & 31,15 & 31,23 & 33,20 & 17,58 & 22,13 & 28,97 \\
\hline & MI_DGHIK & & $\mathbf{5 4 , 5 7}$ & 68,38 & 32,00 & 55,68 & & 32,30 & 37,52 & & 22,41 & 32,29 \\
\hline & MC_DGHIK & & 33,90 & 51,40 & 23,03 & 38,82 & & 38,27 & 47,51 & & 25,52 & 42,67 \\
\hline \multirow{4}{*}{ Norway } & L_DGHIK & 95,88 & 99,69 & 97,89 & 98,15 & 96,94 & 62,86 & 63,63 & 65,00 & 56,39 & 52,76 & 59,98 \\
\hline & M_DGHIK & 95,24 & 97,65 & 98,70 & 91,03 & 94,95 & 59,23 & 59,39 & 62,95 & 49,85 & 54,44 & 59,36 \\
\hline & S_DGHIK & 79,89 & 92,37 & 94,51 & 75,58 & 84,61 & 58,12 & 55,25 & 59,15 & 42,97 & 49,83 & 54,75 \\
\hline & MI_DGHIK & & 87,28 & 92,54 & 65,33 & 78,13 & & 58,16 & 62,40 & & 53,24 & $\mathbf{5 9 , 8 7}$ \\
\hline \multirow{4}{*}{ Ireland } & L_DGHIK & 96,43 & 100,00 & 99,52 & 85,75 & 90,69 & 44,94 & 65,41 & 63,91 & 23,67 & 40,02 & 44,89 \\
\hline & M_DGHIK & 94,48 & 98,17 & 98,56 & 61,95 & 80,54 & 45,74 & 48,28 & 53,02 & 23,33 & 31,13 & 42,32 \\
\hline & S_DGHIK & 80,00 & 90,37 & 93,60 & 42,74 & 63,14 & 46,68 & 46,64 & 50,51 & 25,83 & 30,08 & 40,65 \\
\hline & VS_DGHIK & & & 66,08 & & 36,04 & & & 60,53 & & & 51,56 \\
\hline \multirow{6}{*}{ Spain } & L_DGHIK & 98,43 & 98,11 & 99,90 & 93,23 & 99,74 & 36,86 & 54,67 & 61,35 & 18,68 & 35,63 & 48,62 \\
\hline & M_DGHIK & 93,76 & 96,25 & 98,67 & 85,85 & 97,81 & 33,56 & 44,32 & 50,63 & 20,32 & 32,68 & 40,01 \\
\hline & S_DGHIK & 80,15 & 88,77 & 95,68 & 74,34 & 93,08 & 30,67 & 41,80 & 44,59 & 19,28 & 31,62 & 38,44 \\
\hline & MI_DGHIK & & 45.91 & & 33.24 & & & 48.73 & & & 34.52 & \\
\hline & MC_DGHIK & & 69.84 & & 57.61 & & & 47.72 & & & 37.23 & \\
\hline & VS_DGHIK & & 49.59 & 67,89 & 36.98 & 63,30 & & 48.37 & 57,34 & & 35.50 & 42,54 \\
\hline \multirow{5}{*}{ Germany } & L_DGHIK & 97,82 & 99,44 & 99,44 & 95,34 & 96,65 & 53,40 & 67,06 & 68,82 & 27,11 & 47,41 & 48,51 \\
\hline & M_DGHIK & 90,40 & 99,01 & 98,63 & 81,97 & 93,86 & 44,41 & 52,56 & 58,70 & 24,13 & 35,03 & 48,06 \\
\hline & S_DGHIK & 82,13 & 93,21 & 97,21 & 57,02 & 87,98 & 52,92 & 49,52 & 55,33 & 29,68 & 35,85 & 47,95 \\
\hline & MI_DGHIK & 74,08 & 74,48 & 91,80 & 34,15 & 78,44 & 54,20 & 62,75 & 60,57 & 34,33 & 50,08 & 54,29 \\
\hline & MC_DGHIK & 46,14 & 86,32 & 78,27 & 47,02 & 64,77 & 49,19 & 56,60 & 65,85 & 36,26 & 41,32 & 60,26 \\
\hline \multirow{5}{*}{ Slovak } & L_DGHIK & & 98,28 & 99,46 & 66,14 & 96,58 & 25,33 & 31,92 & 41,88 & 9,92 & 18,78 & 29,92 \\
\hline & M_DGHIK & & 97,94 & 98,79 & 60,23 & 84,97 & 22,30 & 38,63 & 42,52 & 9,55 & 30,28 & 37,58 \\
\hline & S_DGHIK & & 90,95 & 97,83 & 44,55 & 76,06 & 29,78 & 45,55 & 50,83 & 16,67 & 36,67 & 46,87 \\
\hline & MI_DGHIK & & 79,06 & 94,50 & 39,10 & 67,11 & & 63,22 & 67,49 & & 52,21 & 62,52 \\
\hline & MC_DGHIK & & 63,49 & 75,99 & 30,92 & 50,32 & & 55,81 & 73,56 & & 42,94 & 67,34 \\
\hline \multirow{4}{*}{ Slovenia } & L_DGHIK & & 99,60 & 100,00 & 96,05 & 98,51 & & 46,86 & 54,95 & & 31,74 & 42,65 \\
\hline & M_DGHIK & & 98,19 & 100,00 & 87,57 & 97,22 & & 45,52 & 52,12 & & 35,56 & 45,24 \\
\hline & S_DGHIK & & 95,00 & 95,11 & 69,16 & 81,72 & & 53,99 & 51,66 & & 44,80 & 46,64 \\
\hline & MI_DGHIK & & 92,63 & 92,48 & 55,12 & 78,34 & & $\mathbf{5 7 , 3 7}$ & 58,90 & & 46,80 & 52,67 \\
\hline
\end{tabular}

Note: (1) The last year for Slovenia is 2009, for Ireland 2007, for Slovak 2009 and for Portugal 2009.

(2) Includes NACE categories of DFHIKO.

(3) Data includes NACE categories of DFGHIJKO.

(4) For ES the year is 2003.

(5) Blank cell indicates data not available. 
The distribution pattern of the proportion of ICT using enterprises across size classes of enterprises is quite contrasting with the distribution pattern of the proportion of workers using ICT across size classes of enterprises the larger size class has much higher proportion of enterprises with ICT but lower proportion of workers using ICT and vice versa. An implication is that where there is more ICT capital, fewer workers use it leading to productivity growth, if at all, of a small section of the workers. Together with this, overall low level of the workers' participation in ICT use has been reflected in the low growth of overall labour productivity.

\section{Concluding Observations}

The information and communication technology has become the latest tool of raising labour productivity in the US economy as revealed in a number of studies. It has been noted that this technology help raise productivity not only through larger, faster and efficient processing and dissemination of information, but also through knowledge spill over, further innovation in using the technology and complementary investment. In Lisbon Treaty (2000) EU member states emphasised to build up information society with fast adoption of the technology by the enterprises and also by the households. It was hoped that the technology would soon bring about high growth of productivity in these countries. An optimistic trend was noted regarding the use of ICT as the ICT capital stock increased several folds raising its share in total fixed capital between 5 to 13 percent in these countries in 2005. But its benefit was not reflected in terms of labour productivity growth. On the contrary, the growth rate of labour productivity in most of these countries slowed down.

Several micro level studies for the EU countries and US however established the fact that at firm level ICT raises labour productivity. This micro observation thus apparently contradicts the macro findings for the EU countries, which needs reconciliation. It is noted above that in the EU countries most of the enterprises with 10 or more workers installed ICT devices. For instance, computer was installed by 93 percent of the enterprises in 2003 which rose to 98 percent by 2009 . However, there is a difference between the small and large enterprises in the use of sophisticated ICT - the more the level of sophistication the lower is the proportion of small enterprises installing them. Benefits from advanced ICT are thus appropriated more by the large enterprises which are fewer in number as compared to small enterprises.

ICT raises skill and productivity of a worker by enabling it to process, store, retrieve and access data of large volume with high speed as well as enabling easy access to knowledge, its diffusion and discourse with other people. However, barely half of the workforce use computers and around a third used internet during 2003-05 implying under preparedness of the enterprises to effectively utilise ICT through organisational restructuring needed for the new job description of workers to use new technology. Deployment of workers for the use of ICT is further slowed down due to the fact that it is very difficult, or at least highly costly, for the enterprises to train their workers in the new technology and at the same time under the EU labour law it is hard to retrench a worker without ICT skill for the recruitment of a young one possessing the required skill (Note 11). It is thus obvious that the major benefit from ICT is yet to be translated into high productivity growth of the workers at the economy-wide level.

The proportion of ICT using workers is lower for the small enterprises and thus their numerous workers not often benefit from the advanced ICT which are more concentrated in the large enterprises. The workers of the large enterprises would only gain productivity. Empirical estimation based on micro data at the enterprise level may show up higher productivity associated with the use of ICT because of more the presence of large enterprises using advanced ICT in the select sample of enterprises. Since the number of workers employed by the limited number of ICT using firms is small, their higher productivity would not be reflected in the overall economy where majority of the workers, who are yet to use the technology, have not experienced any significant growth of productivity. Moreover, the benefits obtained by a few large enterprises may be at the expense of others, as noted by Spiezia and Vivarelli (2002).

Very small enterprises consisting of mini and micro enterprises are the most neglected lot among all the size classes of enterprises. Even systematic data on the ICT use by mini and micro enterprises are not collected in most of the EU countries despite the fact that they account for 90 to 96 percent of the enterprises employing 23 to 50 percent of the workforce in these countries. Obviously, any rise in the productivity of these workers will pull up the productivity for the economy and conversely, if they remain stagnant and only some larger enterprises raise their labour productivity, the gain for the economy in terms of overall labour productivity growth would be minimal and this is what happened in many of the EU countries. On the basis of limited available data it is found that the least proportion of the ICT using enterprises belong to the mini and micro size classes and the disparity with the larger size classes widens if one considers slightly more advanced technology like broadband rather than simple internet. Although the proportion of workers using the technology was in general very low, the 
distribution of the proportion of workers using ICT across size classes is diametrically opposite to the distribution of the proportion of ICT using enterprises in a majority of the countries for which data on very small enterprises are available. Thus mini and micro size classes with least proportion of enterprises with ICT installation, with less sophisticated technology and probably with the least amount of ICT capital, employ relatively larger proportion of workers who use ICT. The larger enterprises on the other hand with more sophisticated and larger quantity ICT capital employ fewer workers who handle this technology. An implication of this is the growth of productivity of selected high ICT skilled workers in larger enterprises leaving rest of the workforce to benefit least from the technology. It is obvious under this situation that the productivity growth of the workers as a whole would be stunted.

It follows from the above discussion that the enterprise modernisation process needs to be more inclusive. The small, mini and micro enterprises that are the basic foundation of these economies should be given due and effective attention so that they can install latest high technology like ICT and train their workers to use the technology. A broad based approach, possibly in the form of technology mission, to modernisation of the vast number of enterprises through installing latest information and communication technology and skill up gradation of numerous workers is required. Only then one can expect economy-wide productivity growth, substantial knowledge creation and spill over and its absorption for further innovation and this would bringing about the kind of dynamism and knowledge society desired by the member states in Lisbon Treaty.

\section{References}

Andersson, B., \& Ådahl, M. (2005). Den "nya ekonomin” och svensk produktivitet på 2000-talet, Penning- och valutapolitik 1. Sveriges riksbank, pp. 47-68.

Aghion, P., Caroli, E., \& Garcia-Peñalosa, C. (1999). Inequality and Economic Growth: the Perspective of the New Growth Theories. Journal of Economic Literature, 37(3), 1615-1660. http://dx.doi.org/10.1257/jel.37.4.1615

Baruch, L. (2001). Intangibles: Management, Measurement, and Reporting. Washington, D.C.: Brookings Institution.

Basu, S., John, G. F., Oulton, N., \& Srinivasan, S. (2004). The Case of the Missing Productivity Growth, Or Does Information Technology Explain Why Productivity Accelerated in the United States But Not in the United Kingdom? NBER Macroeconomics Annual 2003 (pp. 9-63). The MIT Press.

Biswas, P. K., \& Baptista, A. (2012). Institutions and Micro Enterprises Demography: A Study of Selected EU Countries, 1997-2006. Journal of Small Business and Entrepreneurship, 25(3), 283-306.

Black, S. E., \& Lynch, L. M. (2001). How to Compete: The Impact of Workplace Practices and Information Technology on Productivity. Review of Economics and Statistics, 83(3), 434-445. http://dx.doi.org/10.1162/00346530152480081

Bloom, N., Sardun, R., \& van Reenen, J. (2007). Americans Do I.T. Better: US Multinationals and the Productivity Miracle. CEP Discussion Paper no. 788.

Bresnahan, T. F. (undated) The Mechanisms of Information Technology's Contribution to Economic Growth, prepared for presentation at the Saint-Gobain Centre for Economic Research. Retrieved from http://www.stanford.edu/ tbres/research/mechanisms_of_it_contribution.pdf, viewed on 12/12/2009

Bresnahan, T., \& Saloner, G. (1996). Large Firms' Demand for Computer Products and Services: Competing Market Models, Inertia, and Enabling Strategic Change, in: David B. Yoffie (ed.). Colliding Worlds: The Merging of Computers, Telecommunications, and Consumer Electronics. Harvard University Press.

Bresnahan, T., \& Trajtenberg, M. (1995). General Purpose Technologies: Engines of Growth? Journal of Econometrics, 65(1), 83-108. http://dx.doi.org/10.1016/0304-4076(94)01598-T

Brynjolfsson, E. (2003). Computing Productivity: Firm-level Evidence. MIT Working Paper 4210-01. MIT.

Brynjolfsson, E., \& Hitt, L. (2000). Beyond Computation: Information Technology, Organizational Transformation and Business Performance. The Journal of Economic Perspectives, 12(4), 23-48. http://dx.doi.org/10.1257/jep.14.4.23

Brynjolfsson, E., \& Hitt, L. (2003). Computing Productivity: Firm-Level Evidence. The Review of Economic and Statistics, 85(4), 793-808. http://dx.doi.org/10.1162/003465303772815736

Brynjolfsson, E., \& Kahin, B. (2000). Understanding the Digital Economy: Data, Tools and Research. Cambridge, MIT Press. 
Brynjolfsson, E., McAfee, A., Zhu, F., \& Sorell, M. (2006). Scale without Mass: Business Process Replication and Industry Dynamics. Harvard Business School Technology \& Operations Mgt. Unit Research Paper No. 07-016.

Corrado, C. H., \& Sichel, D. (2006). Intangible Capital and Economic Growth. Finance and Economics Discussion Series. Washington, D.C.: Divisions of Research \& Statistics and Monetary Affairs, Federal Reserve Board.

Caroli, E., \& van Reenen, J. (2001). Skill Biased Organizational Change? Evidence from a Panel of British and French Establishments. Quarterly Journal of Economics, 116(4), 1149-1192. http://dx.doi.org/10.1162/003355301753265624

Demunteer, C. (2006). How Skilled are Europeans in Using Computers and the Internet? Statistics in Focus, Eurostat.

Gust, C., \& Marquez, J. (2002). International Comparisons of Productivity Growth: the Role of Information Technology and Regulatory Practices. International Finance Discussion Papers. Number 727, reproduced In: Labour Economics, 2004, 11(1), pp. 33-58.

Jorgenson, D. W., \& Stiroh, K. J. (2000). Raising the Speed Limit: U.S. Economic Growth in the Information Age. Brookings Papers on Economic Activity, 1, 125-211. http://dx.doi.org/10.1353/eca.2000.0008

Karpaty, P. (2007). Productivity Effects of Foreign Acquisitions in Swedish Manufacturing: The FDI Productivity Issue Revisited. International Journal of the Economics of Business, 14(2), 241-260. http://dx.doi.org/10.1080/13571510701344038

Nakamura, L. (1999). Intangibles: What Put the New in the New Economy? Federal Reserve Bank of Philadelphia, Business Review, (July/August), pp. 3-16.

Nakamura, L. (2001). What is the US Gross Investment in Intangibles? (At Least) One Trillion Dollars a Year! Federal Reserve Bank of Philadelphia, Working Paper No. 01-15.

Nakamura, L. (2003). The Rise in Gross Private Investment in Intangible Assets Since 1978. Mimeo, Federal Reserve Bank of Philadelphia.

Oliner, S., \& Sichel, D. E. (2000). The Resurgence of Growth in the Late 1990s: Is Information Technology the Story? Journal of Economic Perspectives, 14(Fall), 3-22. http://dx.doi.org/10.1257/jep.14.4.3

Oliner, S., \& Sichel, D. E. (2002). Information Technology and Productivity: Where Are We Now and Where Are We Going? Federal Reserve Bank of Atlanta, Economic Review, Third Quarter.

Pettersson, B. (2009). The Connection between IT Investments, Competition, Organisational Changes and Productivity. Economic Review, 2, 72-85.

Saloner, G., \& Steinmueller, W. E. (1995). Demand for Computer Products and Services by Large European Organizations. Stanford GSB Research Paper Series, No. 1370.

Solow, R. M. (1987). We'd Better Watch Out. NY Timers, Book Review, July $12^{\text {th }}$.

Spiezia, V., \& Vivarelli, M. (2002). Innovation and Employment: A Critical Survey. In: N. Greenan, Y. L'Horty and J. Mairesse, (Eds.), Productivity, Inequality and the Digital Economy. Cambridge, M. A.: MIT Press.

Stiroh, K. J. (2002). Information Technology and the U.S. Productivity Revival: What Do the Industry Data Say? American Economic Review, 92(5), 1559-1576. http://dx.doi.org/10.1257/000282802762024638

van Ark, B., Melka, J., Mulder, N., Timmer, M., \& Ypma, G. (2002). ICT Investment and Growth Accounts for the European Union, 1980-2000. Final Report on ICT and growth accounting for the DG Economics and Finance of the European Commission, Brussels. Retrieved October 12, 2009, from http://www.eco.rug.nl/GGDC/dseries/Data/ICT/euictgrowth.pdf

van Ark, B. (2002). Measuring the New Economy: An International Comparative Perspective. Review of Income and Wealth, 48(1), 1-14. http://dx.doi.org/10.1111/1475-4991.00036

van Ark, B., \& Inklaar, R. (2005). Catching up or Getting Stuck? Europe's Trouble to Exploit ICT's Productivity Potential. Research Memorandum, GD-79, University Groningen.

van Ark, B. (2006). Europe's Productivity Gap: Catching Up or Getting Stuck? Economics Programme Working Paper Series, The Conference Board Europe and Growth and Development Center of the University of Groningen. 


\section{Notes}

Note 1. As Solow (1987) stated, "You can see the computer age everywhere but in the productivity statistics". Some important early studies on IT capital's contribution to productivity are Oliner and Sichel (2000), Oliner and Sichel (2002), Jorgenson and Stiroh (2000) and Stiroh (2002).

Note 2. Substantial growth of intangible capital, like, software, other computerised information, or spending on innovative property (such as R\&D) and their contribution of to productivity growth are discussed in Nakamura (1999), Nakamura (2001), Nakamura (2003), Lev (2001), Basu, Fernald, Oulton, and Srinivasan (2004), and Corrado, Hulten and Sichel (2006).

Note 3. According Bresnahan (undated), "key technological advances yield little value unless they are widely adopted. Once widespread adoption can be achieved, however, large value to society follows".

Note 4. Brynjolfsson and Hitt (2000) and Bresnahan (undated) made a detailed discussion on the different kinds of complementary investments and co-invention made by the firms in order to fully exploit this "general purpose technology". The most important characteristic of a general purpose technology is that its effects extend well beyond the industry producing it. However, for the realisation of full benefit from it firms need to make complementary investments. In the case of ICT diffusion Bresnahan (undated) noted: "Some IT applications are associated with substantial co-invention costs. These are costs that a user needs to bear up front, before getting any value out of the application. The coinvention costs include the costs of programming to make a technology useful in a business information system, the costs of training workers to use it, and, importantly, the costs of inventing a business purpose for the system and organizational change to use it effectively".

Note 5. For instance, van Ark et al. (2002) and Gust and Marquez (2002) made detailed analyses of productivity trends and noted the deceleration of TFP and labour productivity in overall EU and Japan. Gust and Marquez (2002) observed that TFP accelerated in 1995-2000 as compared to 1980-95 in the United States, Finland, Sweden, Australia, and Canada. van Ark et al. (2002) made a comparison of the EU and the US based on aggregate national accounts data and found that TFP and labour productivity growth rates were higher in the EU than in the US during 1980-95. Thereafter productivity decelerated in the EU and accelerated in the US leading to around 3/4 percentage point faster growth rate in the US than EU.

Note 6. Basu et al. (2004) noted that for UK business cycle phenomenon was unlikely to be a significant factor that contributed to deceleration of labour productivity.

Note 7. For a discussion on US see Brynjolfsson et al. (2000) who estimated very high returns on ICT investments by large firms. EC (2008) notes that the core ICT use metrics used in the project (computer use, e-sales, e-purchases, fast internet enabled or using employees) show reasonably consistent, positive, labour productivity effects at firm level across manufacturing industries in all countries (p. 2).

Note 8. See also Basu etal. (2004).

Note 9. As Brynjolfsson et al. (2008) noted "Firms that successfully use IT to embed and diffuse innovations grow relatively rapidly at the expense of other firms, leading to winner-take-all dynamics and hence greater concentration at the industry level".

Note 10. Eurostat data compiled in Biswas and Baptista (2012).

Note 11. It was observed by Gust and Marquez (2002) that the countries with highly regulatory environment, especially relating labour market practices usually adopt ICT more slowly and also had slower total factor productivity growth. 